\title{
ПРИБЛИЖЕННАЯ 3D МОДЕЛЬ ЭЛЕКТРОМАГНИТНЫХ КОЛЕБАНИЙ В ВОЛНОВОДНЫХ КРЕСТООБРАЗНЫХ СОЕДИНЕНИЯХ С ДИЭЛЕКТРИКОМ
}

\author{
А. В. СТРИЖАЧЕНКО \\ Харьковский национальный университет им. В. Н. Каразина, \\ Украина, Харьков, 61077, пл. Свободы, 4
}

\begin{abstract}
Аннотация. В работе предложена трехмерная электродинамическая модель гибридных электромагнитных колебаний в волноводном соединении цилиндрический-прямоугольный волноводы с диэлектрическим заполнением цилиндрического волновода. Для решения векторной задачи применен метод частичных областей с выделением общей области связи волноводов и представлением поля в ней в виде суперпозиции полей парциальных собственных волн волноводов. Проведена классификация собственных типов колебаний: собственных резонансов разветвления на запредельных модах и резонансов волноводно-диэлектрического типа. Исследуемая структура может использоваться для измерения электрических параметров диэлектрических образцов как цилиндрической, так и прямоугольной формы поперечного сечения. Так как спектральные характеристики разветвления в основном определяются размером центральной области связи волноводов и электрическими параметрами той части диэлектрика, который там находится, то измерения носят локальный характер.
\end{abstract}

Ключевые слова: волноводное разветвление; гибридное колебание; электродинамическая модель; диэлектрик

\section{1. ВВЕДЕНИЕ}

Электромагнитным колебаниям в крестообразных и Т-образных волноводных разветвлениях посвящено значительное число работ [1-8]. Исследовались свободные колебания в разветвлении прямоугольных волноводов [1], аксиально-симметричные и несимметричные колебания в разветвлении цилиндрических волноводов [2], а также квазисобственные колебания в сочленениях и разветвлениях волноводов [3]. Это объясняется их широким использованием в технике сверхвысоких частот (СВЧ) в качестве составных частей пассивных и активных приборов [4], измерительных устройств для определения электрических параметров диэлектриков [5].
Задачи о разветвлениях с различной формой поперечного сечения волноводов относятся к категории наиболее сложных векторных краевых задач. Это связано с представлением полного поля в виде суперпозиции полного набора полей $H$ и $E$ типов волн во всех волноводах. Работы $[4,6,7]$ посвящены точному моделированию незаполненных тройниковых и других соединений волноводов. В [4] в дополнение к методу частичных областей (МЧО) использована концепция расширенного граничного условия, означающая, что если поля непрерывны на искусственно введенной граничной поверхности внутри замкнутого объема, то они должны быть непрерывны и на других поверхностях в этом объеме. Эта концепция облегчает анализ сложных краевых задач с ис- 


\section{БИБЛИОГРАФИЧЕСКИЙ СПИСОК}

1. Стрижаченко, А. В. Электродинамика волноводных разветвлений с анизотропным заполнением. Известия вузов. Радиоэлектроника, Т. 51, № 8, С. 55-61, 2008. URI: http://radio.kpi.ua/article/view/S0021 347008080074.

2. Макеев, Ю. Г.; Рудь, Л. А.; Острицкая, С. Ю. Собственные аксиально-несимметричные колебания разветвления круглого и радиального волноводов. $\mathrm{Pa}$ диотехника и электроника, Т. 39, № 10, С. 1497-1502, 1994.

3. Шестопалов, В. П.; Кириленко, А. А.; Рудь, Л. А. Резонансное рассеяние волн. Волноводные неоднородности. К.: Наукова думка, 1986.

Поступила в редакцию 25.10.2016
4. Wu, K.-L.; Yu, M.; Sivadas, A. Novel modal analysis of a circular-to-rectangular waveguide T-junction and its application to design of circular waveguide dual-mode filters. IEEE Trans. Microwave Theory Tech., Vol. 50, No. 2, P. 465-473, 2002. DOI: $\underline{10.1109 / 22.982}$ 225 .

5. Strizhachenko, A. V. The measurement of permittivity tensor of uniaxial crystals with tetragonal and hexagonal symmetry at microwaves. Electrical Power Eng. Frontier, Vol. 2, No. 1, P. 17-21, 2013. URI: http://www.academicpub.org/epef/paperInfo.aspx?PaperI $\mathrm{D}=13820$

6. Кириленко, А. А.; Кулик, Д. Ю.; Стешенко, С. А. Ключевой алгоритм метода частичных областей в анализе резонансных штырей, тройниковых, турникетных и некоторых других многоплечих соединений. Радиофизика и электроника, Т. 7, № 4, С. 11-18, 2016. DOI: $10.15407 / \mathrm{rej} 2016.04 .011$.

7. Krauss, P.; Arndt, F. Rigorous mode-matching method for the modal analysis of the T-junction circular to sidecoupled rectangular waveguide. Proc. IEEE MTT-S Int. Microwave Symp. Dig., 16-20 May 1995, Orlando, Fl, USA. IEEE, 1995, P. 1355-1358. DOI: 10.1109/MW SYM.1995.406222.

8. Рудь, Л. А.; Сиренко, Ю. К.; Шестопалов, В. П.; Яшина, Н. П. Алгоритмы решения спектральных задач, связанных с открытыми волноводными резонаторами. Х.: ИРЭ АН УССР, 1986, 26 с. Препринт № 318/ НАН Украины, «Институт радиофизики и электроники».

9. Макеев, Ю. Г.; Моторненко, А. П. Собственные электромагнитные колебания в резонаторе на запредельных волноводах. ЖТФ, Т. 69, № 4, С. 84-88, 1999. URI: http://journals.ioffe.ru/articles/36026.

После переработки 19.10.2017 